\title{
Getting it Right: Directors' assessment of information
}

\author{
O’Donnell, K.*, Hicks, B., Streeter, J. \& Shantapriyan, P. \\ University of Tasmania
}

\begin{abstract}
Purpose: The purpose of this research is to examine a role for Information and Process scepticism in non-delegable director duties. We draw upon auditing literature to guide an understanding of scepticism.

Design: This is a conceptual paper, drawing upon archival material, including statute law, case law, regulatory guidance material and media releases in Australasia.

Research Implications: We present arguments that challenge us to understand the process of information, judgment and actions of directors as a neuroeconomic phenomenon.

Practical Implications. Directors do have a different role to that of auditors, but in our view the desirability of embracing scepticism does not defeat their responsibility on behalf of shareholders. By applying information and process scepticism, directors of companies might reduce the likelihood and magnitude of litigation costs and out of court settlements.

Novelty: To date, whether or not a director has exercised an appropriate level of reasonable care and skill and/or due diligence has been a matter for courts to decide. Such retrospective analysis leaves directors vulnerable to the uncertainty of whether their individual interpretation of diligence matches up to that of the presiding judge. We provide directors with a scepticism framework to apply to information and processes provided by people on whom the directors may rely.
\end{abstract}

\section{Keywords:}

Scepticism, corporate accountability, directors’ duties, non-delegable duties, decision

\section{Classification:}

Conceptual paper.

* Corresponding author: Kerri.ODonnell@utas.edu.au 